\title{
Oral Symptoms and Bone Observations in Odonto-Hypophosphatasia
}

\section{Seiko Yamamoto-Nemoto', Rina Shimada', Hanako Tajima ${ }^{2}$, Emiko Iwasawa', Yoko Shimizu', Elif Bahar Tuna³, Kei Ogawa1, Atsushi Watanabe", Takehiko Shimizu1}

${ }^{1}$ Department of Pediatric Dentistry, Nihon University School of Dentistry at Matsudo, Matsudo, Japan

${ }^{2}$ Department of Pediatrics, Nippon Medical School, Tokyo, Japan

${ }^{3}$ Department of Pediatric Dentistry, Istanbul University Faculty of Dentistry, Istanbul, Turkey

${ }^{4}$ Department of Molecular and Medical Genetics, Nippon Medical School, Tokyo, Japan

Email: yamamoto.seiko@nihon-u.ac.jp

How to cite this paper: Yamamoto-Nemoto, S., Shimada, R., Tajima, H., Iwasawa, E., Shimizu, Y., Tuna, E.B., Ogawa, K., Watanabe, A. and Shimizu, T. (2016) Oral Symptoms and Bone Observations in OdontoHypophosphatasia. Open Journal of Stomatology, 6, 245-251.

http://dx.doi.org/10.4236/ojst.2016.612030

Received: October 29, 2016

Accepted: December 2, 2016

Published: December 5, 2016

Copyright (C) 2016 by authors and Scientific Research Publishing Inc. This work is licensed under the Creative Commons Attribution International License (CC BY 4.0).

http://creativecommons.org/licenses/by/4.0/

(c) (i) Open Access

\begin{abstract}
Hypophosphatasia (HPP) is an inherited skeletal disease caused by mutation of the gene encoding tissue non-specific alkaline phosphatase (TNSALP). Odonto-HPP is well known as the mildest of HPP. The manifestations involve only the teeth, such as premature primary teeth exfoliation caused by reduction of alveolar bone, enlarged dental pulp chamber, and dental defects. We report a case of a 9-years-old boy who developed HPP. He was observed from the primary dentition to the mixed dentition period. At initial presentation at our hospital, he had multiple premature exfoliation of primary teeth and reduction of the alveolar bone. HPP was suspected due to the low level of ALP activity in serum, his oral manifestation, and dental history. He was referred to a physician for the final diagnosis. Therefore his compound heterozygote mutations, c.1559 delT (T/delT) and c.407G > A (G/A), were found in TNSALP and he diagnosed with odonto-HPP. Even though these mutations were reported as being involved in odonto-HPP, his mineral densities tended to be lower than that of his age. It is therefore necessary to investigate the bone mineralization level in odontoHPP without other bone symptoms. Moreover, ongoing enzyme-replacement therapy in odonto-HPP might improve dental abnormality and bone disorders.
\end{abstract}

\section{Keywords}

Hypophosphatasia, Odonto-HPP, Tissue Non-Specific Alkaline Phosphatase

\section{Introduction}

Hypophospatasia (HPP) is an inherited disorder of bone and teeth caused by mutations in the gene encoding tissue non-specific alkaline phosphatase (TNSALP). TNSALP is 
expressed in the liver, kidney, and bone, and is present systemically in the blood in a secreted form. In the absence of TNSALP, accumulated inorganic pyrophosphate inhibits local mineralization and leads to hypomineralization disorders. The biochemical diagnostic markers of this disease are a reduction of alkaline phosphatase (ALP) in the serum, increased phosphoethanol-amine (PEA) in the urine, and increased serum pyridoxal-5'-phosphate (PLP). The clinical severity of HPP varies widely. There are 6 forms of clinical phenotypes, based on the age of onset: perinatal lethal, perinatal benign, infantile, childhood, adult, and odonto-HPP. The perinatal form is the most severe type diagnosed, such as rickets or osteomalacia, and the mildest form is odonto-HPP, which has only tooth manifestations, such as premature primary teeth exfoliation, large dental pulp chamber [1]. The disease follows both recessive and dominant inheritance patterns. The variable symptoms of HPP result from the inheritance pattern, dominant-negative effects, or compound heterozygosity in milder case [2].

Among several studies of HPP, there are only a few case reports of odonto-HPP. This case report describes the oral history of a nine-year-old boy who presented with numerous exfoliation of primary teeth at the age of one-and-a-half years. He was diagnosed on the basis of clinical examinations and oral symptoms at the age of nine years after visiting a dentist. In addition to clinical and radiographic findings, low ALP levels, increased urinary PEA were diagnostic markers of the disease.

\section{Description of Case}

The patient was a nine-year-old boy who developed hypophosphatasiaat one-and-ahalf-years old. His first indication was mandibular anterior tooth movement at the age of 11 months. Although traumatic injury was suspected as the cause, he then presented with premature exfoliation of primary mandibular central incisors. Thereafter, the primary mandibular left lateral incisor was defluxion and the primary maxillary incisors and left canine teeth moved. At the age of three years, the primary maxillary right canine, primary maxillary left central incisor, and primary mandibular left canine underwent premature defluxion at the time of the first consultation at our hospital (Figure $1(\mathrm{a})$ ). His periodontal depth ranged from two to six $\mathrm{mm}$, and the mobile teeth had particularly deep periodontal pockets. Moreover, gingival retraction and exposed root surfaces, with root caries, were present, and his plaque control record was 50\%. Dental Xrays showed an enlarged dental pulp chamber and reduced alveolar bone around deciduous teeth (Figure $1(\mathrm{c})$ ). The roots were short and the canals were stenosed with the permanent teeth.

He was treated with resin filling for caries and wire resin fixation and dentures for esthetic reasons and to recover dental occlusion. We also instructed him in performing oral hygiene. From the age of nine years, primary teeth were smoothly exchanged for permanent teeth (Figure 1(b)). Although it seems that his eruption of teeth rete was very slow. The alveolar bone levels of the permanent anterior teeth were increased and movement of permanent teeth was not observed (Figure 1(d)).

Eventually HPP was suspected based on his low serum ALP levels and his oral ma- 

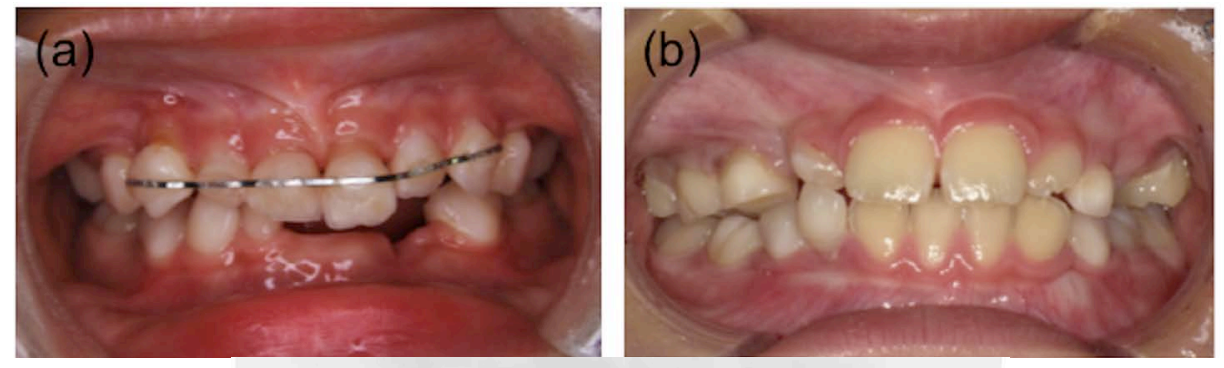

(c)
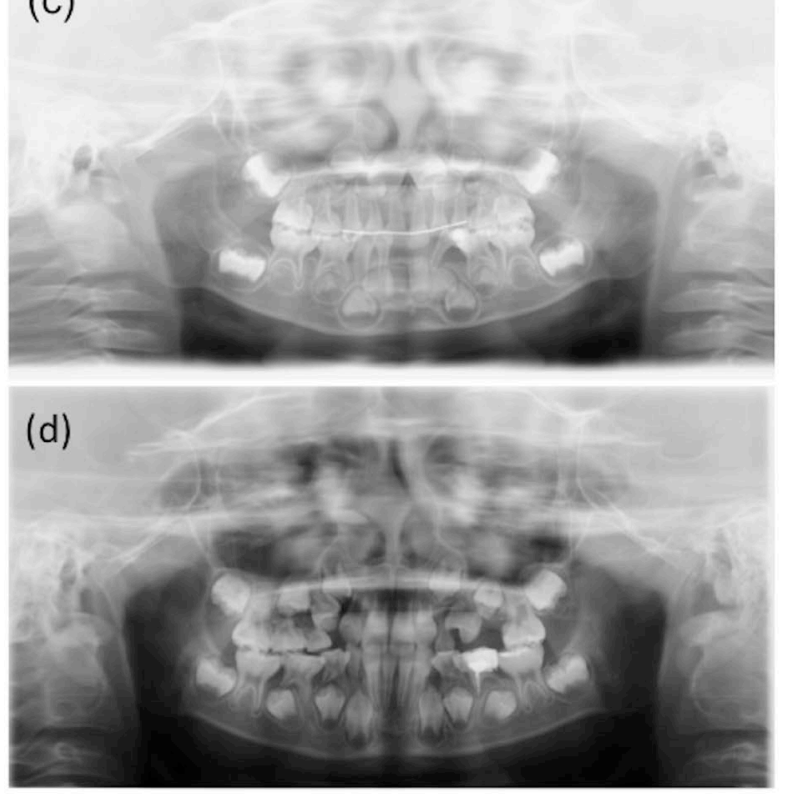

Figure 1. (a) The mandibular anterior primary teeth fell out and the primary maxillary anterior teeth demonstrated mobility, gingival retraction, and exposed root surfaces with root caries. No inflamed gum was observed around these teeth. This image was taken at the age of 3 years and 11 months; (b) Eruption of eight permanent incisors are shown. The permanent teeth had no mobility and had deep periodontal pockets. The oral photographs showed no inflammation of the gums. This image was taken at 9 years and 5 months old; (c) The alveolar bone around the deciduous teeth was decreased. The maxillary left canine was slanted, but there was no root resorption. The image was taken at the age of 3 years and 11 months. The alveolar bone atrophy and root and dental pulp chamber shape anomalies were observed as the radiographic dental clinical marker of HPP; (d) The alveolar bone levels of the permanent anterior teeth were increased and irregularly impacted premolars were observed. The roots were short and the canals were stenosed with the permanent teeth. This image was taken at 9 years and 5 months old.

nifestations, loss of numerous primary teeth without inflammation and infection, and sparse alveolar bone, and his dental history. We referred him to a physician for the final diagnosis at the age of nine and four months. His height was $134.1 \mathrm{~cm}(+0.33 \mathrm{SD})$ and his weight was $26.1 \mathrm{~kg}(-0.5 \mathrm{SD})$. He had been born by vaginal delivery at 40 weeks and two days pregnancy, with a birth weight of $3556 \mathrm{~g}$. He had never suffered a fracture and bone pain, and took part in gymnastics and soccer. His ALP activity level in serum was $266 \mathrm{IU} / \mathrm{L}$ (reference range at nine-year-old: 400 - $1250 \mathrm{IU} / \mathrm{L}$ ) and PEA in urine was 840 $\mu \mathrm{mol} / \mathrm{g} \mathrm{Cr}(7-70 \mu \mathrm{mol} / \mathrm{g} \mathrm{Cr})$. After the biochemical tests, TNSALP gene sequencing 
was performed and heterozygous c.1559delT (T/delT) and c.407G >A (G/A) mutations were found, which were also confirmed in his parents, who had low ALP activity (mother, $77 \mathrm{IU} / \mathrm{L}$; father, $130 \mathrm{IU} / \mathrm{L}$; reference range in adults: 115 - $359 \mathrm{IU} / \mathrm{L}$ ). His parents were taller than average (mother, $163 \mathrm{~cm}$; father $177 \mathrm{~cm}$ ), and they had no bone pain or teeth problems.

In addition, X-ray examination was performed. The bone mineral densities were measured by dual-energy X-ray absorptiometry (DEXA) (Table 1). His skeletal age as calculated with TW2 20-bone, using his wrist, was 9.0 years (Figure 2(a)). The X-ray of his knee joints showed an almost normal and roughly exterior epiphyseal of the femur (Figure 2(b)). There was no curvature of the four extremities and dimple.

\section{Discussion}

Premature deciduous tooth loss is a major manifestation of HPP. In the case described here, the patient lost primary mandibular anterior teeth, with a suspected traumatic cause. Primary tooth loss can be due to HPP, traumatic injury, periodontitis in children and adolescents, and Papillon-Lefèvre syndrome associated with periodontitis [3]. These periodontal diseases lead to bacterial infection and inflammation because of poor dental hygiene. Blood tests and anaerobic bacteria tests of gingival crevice fluid were negative. HPP, especially the childhood form that has mild bone symptoms and odonto-HPP, should be considered in the differential diagnosis of premature loss of primary teeth that does not present with the diseases described above. Thus, low ALP levels in serum, increased urinary PEA, and increased serum PLP are the important diagnostic

Table 1. Bone mineral content values and the Z-scores in patient.

\begin{tabular}{ccc}
\hline Parts & Bone mineral content $\left(\mathrm{g} / \mathrm{cm}^{2}\right)$ & Z-score \\
\hline Whole body & 0.783 & -0.27 \\
Trunk & 0.591 & -1.12 \\
Pelvis & 0.672 & -0.51 \\
\hline
\end{tabular}
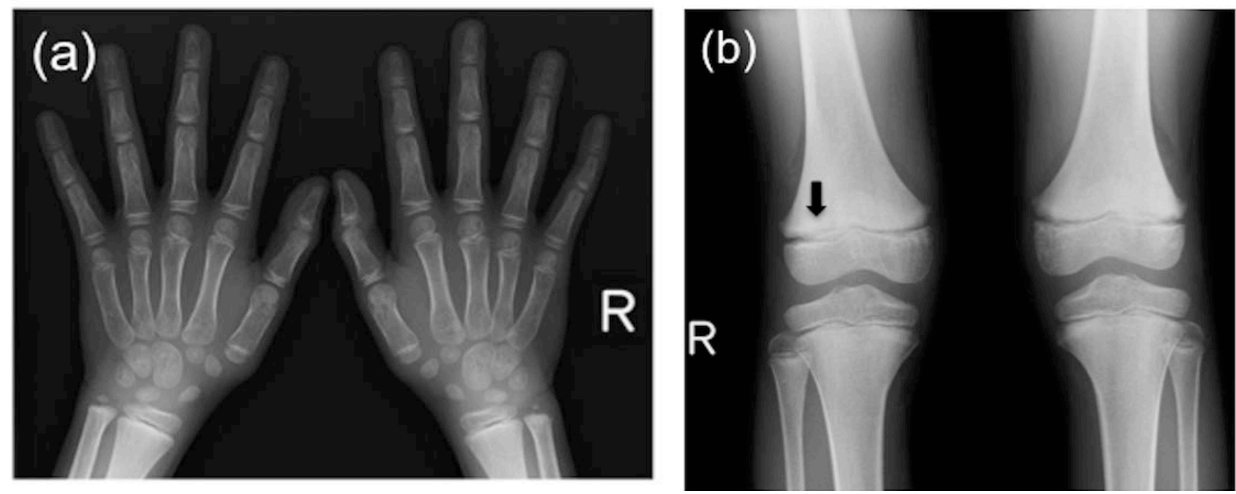

Figure 2. (a) and (b) the X-ray photographs were taken at 9 years and 4 months old. The X-ray of his knee joints showed almost normal appearance. There was no curvature of the four extremities and dimple. However, the femur showed roughly exterior epiphyseal (shown by black arrow). 
biochemical markers of HPP [1]. Alternatively, it has been reported that the clinical markers of HPP are the radiographic dental findings of atrophy of the alveolar bone and root and dental pulp chamber shape anomalies [4]. Our patient was referred to a physician, and diagnosis was made based on low serum ALP levels and the radiographic dental findings.

Numerous studies on dental characterization of HPP have been reported [5] [6], while few reports briefly described the dental management [7] [8]. We observed this patient from the stage of primary dentition to the mixed dentition period. For preventing early defluxion of deciduous teeth and decreasing tooth mobility, fixation of the mobile teeth and denture prosthesis treatment were efficacious. In addition, oral hygiene instruction is important in the dental treatment of HPP patients. His tooth enamel surface looked normal, even though numerous dental caries were found and root surfaces were exposed. Additionally, mobile teeth are easily affected by pulpitis. We suspected an ascending pulpitis as the cause of the dental plaque and the deep pockets. Thus, we reaffirmed the significance of plaque control to prevent early defluxion and ascending pulpitis, as well as dental caries in HPP patients, and the need for regular dental examinations. Moreover, routine oral care of the teeth with low eruption rate were required. The prevalence of uneven occlusal plane causes difficulties in cleansing of the erupting teeth and it is more likely to be affected by dental caries compared to mature permanent teeth. Thus, an oral instruction is considered effective to prevent the dental manifestation of HPP. The alveolar bone increased with eruption and no signs of mobility were observed for the erupted permanent teeth. Therefore, exchange of permanent teeth proceeded as normal without the low eruption rate. His permanent tooth germs in the alveolar bone were unarrayed, so that orthodontic therapy may be necessary to maintain permanent tooth positions.

His compound heterozygose genotype for ALPL mutations has been reported previously in Japanese odonto-HPP patients [9]. c.1559delT is the most frequent allele found in this condition in Japan and may be a founder mutation in the Japanese population. Although the prevalence of odonto-HPP is not clear in Japan, it has been reported that c.1559delT heterozygote carrier frequency is $1 / 480$ in Japanese [10]. While c.407G > A is a mutation found globally [11] [12]. c.1559delT and c.407G > A presents with different phenotypes. Recently, there have been some reports of genotype-phenotype correlations in HPP [4] [12], although these correlations are not completely clear. Therefore, accumulation of genotype-phenotype data is important in the prediction of prognosis in HPP patients. This patient had never shown any bone symptoms without teeth, such as pain or fracture, and his height was normal. However, his Z-score tended to show low mineralization levels and a rough exterior epiphyseal of the femur. The mineralization levels were not stable, because of impending puberty. We recommended investigation of his bone mineralization levels even though he was diagnosed with odonto-HPP. At present, enzyme-replacement therapy is used and achieves significant results in such patients in Japan [1] [13]. The dental abnormality and trend of hypocalcification of bone in this patient may be improved by this treatment. Thus, follow-up of 
the bone mineralization levels is important in odonto-HPP patients to prevent fractures in the future, as treatment may lead to improvement of their dental and bone abnormalities [14].

\section{Acknowledgements}

This research was supported by JSPS KAKENHI Grant Number JP25862035 and JP16K20658 and a grant from the Research Institute of Oral Science, Nihon University School of Dentistry at Matsudo. We would like to thank Editage (www.editage.jp) for English language editing.

\section{References}

[1] Whyte, M.P. (2016) Hypophosphatasia-Aetiology, Nosology, Pasthogenesis, Diagnosis and Treatment. Nature Reviews Endocrinology, 12, 233.

[2] Fauvert, D., Brun-Heath, I., Lia-Baldini, A.S., Belllazi, L., Taillandier, A., Serre, J.L., Mazancourt, P. and Mornet, E. (2009) Mild Forms of Hypophosphatasia Mostly Result from Dominant Negative Effect of Severe Alleles or from Compound Heterozygosity for Severe and Moderate Alleles. BMC Medical Genetics, 10, 51. https://doi.org/10.1186/1471-2350-10-51

[3] Shah, K.M., Karagir, A., Koppikar, R. and Adaki, S. (2013) Papillon Lefevre Syndrome. BMJ Case Reports. https://doi.org/10.1136/bcr-2013-008989

[4] Reibel, A., Manière, M.C., Clauss, F., Droz, D., Alembik, Y., Mornet, E. and Bloch-Zupan, A. (2009) Orodental Phenotype and Genotype Findings in All Subtypes of Hypophosphatasia. Orphanet Journal of Rare Diseases, 4, 6. https://doi.org/10.1186/1750-1172-4-6

[5] Whyte, M.,P., Zhang, F., Wenkert, D., McAlister, W.H., Mack, K.E., Benigno, M.C., Coburn, S.P., Wagy, S., Griffin, D.M., Ericson, K.L. and Mumm, S. (2015) HypophosphatasiaValidation and Expansion of the Clinical Nosology for Children from 25 Years Experience with 173 Pediatric Patients. Bone, 75, 229-239. https://doi.org/10.1016/j.bone.2015.02.022

[6] Wang, Z., Zhang, K., Zhang, Z. and Qiao, W. (2016) Current Concepts in Odontohypophosphatasia form of Hypophosphatasia and Report of Two Cases. BMC Oral Health, 16, 70. https://doi.org/10.1186/s12903-016-0266-0

[7] Lynch, C.D., Ziada, H.M., Buckley, A.L., Sullivan, V.R., Aherne, T. and Aherne, S. (2009) Prosthodontic Rehabilitation of Hypophsphatasia Using Dental Implants: A Review of the Literature and Two Case Reports. Journal of Oral Rehabilitation, 36, 462-468. https://doi.org/10.1111/j.1365-2842.2009.01948.x

[8] Bloch-Zupan, A. (2016) Hypophosphatasia: Diagnosis and Clinical Signs-A Dental Surgeon Perspective. International Journal of Paediatric Dentistry, 26, 426-438. https://doi.org/10.1111/ipd.12232

[9] Taketani, T., Onigata, K., Kobayashi, H., Mushimoto, Y., Fukuda, S. and Yamaguchi, S. (2014) Clinical and Genetic Aspects of Hypophosphatasia in Japanese Patients. Archives of Disease in Childhood, 99, 211-215. https://doi.org/10.1136/archdischild-2013-305037

[10] Watanabe, A., Karasugi, T., Sawai, H., Than Naing, B., Ikegawa, S., Orimo, H. and Shimada, T. (2011) Prevalence of c.1559delT in ALPL, a Common Mutation Resulting in the Perinatal (lethal) Form of Hypophosphatasia in Japanese and Effects of the Mutation on Heterozygous Carriers. Journal of Human Genetics, 56, 166-168.

https://doi.org/10.1038/jhg.2010.161

[11] Brun-Heath, I., Taillandier, A., Serre, J.L. and Mornet, E. (2005) Characterization of 11 
Novel Mutations in the Tissue Non-Specific Alkaline Phosphatase Gene Responsible for Hypophosphatasia and Genotype-Phenotype Correlations. Molecular Genetics and Metabolism, 84, 273-277. https://doi.org/10.1016/j.ymgme.2004.11.003

[12] Zurutuza, L., Muller, F. and Gibrat, J.F. (1999) Correlations of Genotype and Phenotype in Hypophosphatasia. Human Molecular Genetics, 8, 1039-1046.

https://doi.org/10.1093/hmg/8.6.1039

[13] Okazaki, Y., Kitajima, H., Mochizuki, N., Kitaoka, T., Michigami, T. and Ozono, K. (2016) Lethal Hypophosphatasia Successfully Treated with Enzyme Replacement from Day 1 after Birth. European Journal of Pediatrics, 175, 433-437.

https://doi.org/10.1007/s00431-015-2641-2

[14] Mori, M., DeArmey, S.L., Weber, T.J. and Kishnani, P.S. (2016) Case Series-Odontohypophosphatasia or Missed Diagnosis of Childhood/ Adult-Onset Hypophosphatasia? -Call for a Long-Term Follow-Up of Premature Loss of Primary Teeth. Bone Reports, 5, 228-232. https://doi.org/10.1016/j.bonr.2016.08.004

\section{Submit or recommend next manuscript to SCIRP and we will provide best service for you:}

Accepting pre-submission inquiries through Email, Facebook, LinkedIn, Twitter, etc.

A wide selection of journals (inclusive of 9 subjects, more than 200 journals)

Providing 24-hour high-quality service

User-friendly online submission system

Fair and swift peer-review system

Efficient typesetting and proofreading procedure

Display of the result of downloads and visits, as well as the number of cited articles

Maximum dissemination of your research work

Submit your manuscript at: http://papersubmission.scirp.org/

Or contact ojst@scirp.org 